\title{
Evolution du taux de saponification d'acides gras d'huile de colza distribués sous forme de savons calciques au cours du transit digestif chez la vache tarie
}

\author{
F Enjalbert 1, MC Nicot 1, C Bayourthe 2, R Moncoulon 2 \\ ${ }^{1}$ ENVT, Département Elevage et Produits, 31076 Toulouse Cedex; \\ 2ENSAT, Laboratoire d'Ingénierie Agronomique, 31076 Toulouse Cedex, France
}

\begin{abstract}
Les savons calciques d'acides gras ( $A G$ ) sont une forme d'apport lipidique couramment utilisée chez les ruminants, notamment en période de déficit énergétique, car n'entraînant pas de dépression de l'activité cellulolytique dans le rumen (Jenkins et Palmquist, 1984, J Dairy Sci, 67, 978-986).
\end{abstract}

Le but de cet essai était de quantifier, dans les compartiments digestifs successifs, les phénomènes de dissociation - réassociation de savons d'AG d'huile de colza.

L'expérimentation a été réalisée sur 4 vaches taries, de race Holstein, munies de canules à l'entrée du duodénum et à la fin de l'iléon. Ces vaches ont reçu $6 \mathrm{~kg}$ de matière sèche d'ensilage de maïs plante entière, et, sur la base du produit brut, $2 \mathrm{~kg}$ de foin, $1 \mathrm{~kg}$ d'aliment concentré du commerce et $600 \mathrm{~g}$ de savons calciques d'AG d'huile de colza (72,6\% d'AG). La teneur en $A G$ de la ration était de $5,7 \%$. La période d'adaptation aux régimes a duré 1 mois.

Les flux duodénal et iléal de MS ont été mesurés par la technique du double marquage. Les marqueurs (chlorure d'ytterbium marqueur de la phase solide et chrome-EDTA marqueur de la phase liquide) ont été infusés en continu pendant 7 jours. Pendant les 3 derniers jours de marquage, 12 prélèvements de contenus duodénal et iléal ont été récoltés avec mesure immédiate $\mathrm{du} \mathrm{pH}$. Le flux fécal a été mesuré par récolte complète, et les refus ont été récoltés, pesés et analysés.

L'extraction des matières grasses (MG) totales dans les aliments et les prélèvements digestifs a été effectuée par le mélange chloroformeméthanol 2-1 ( $\mathrm{vol} / \mathrm{vol}$ ) puis le mélange hexane-

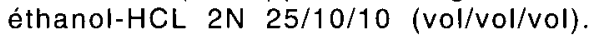
L'extraction des MG autres que les savons calciques a été réalisée par l'éther diéthylique. Le dosage des AG dans ces deux extraits a été effectué après saponification ( $\mathrm{KOH} 1 \mathrm{M}$ dans de l'éthanol à $95 \%$ ), extraction de l'insaponifiable par l'hexane, hydrolyse acide du résidu $(\mathrm{HCl} 6 \mathrm{~N})$ et extraction des $A G$ par l'hexane. Les $A G$ sous forme de savons calciques (AGSC) ont été calculés par différence $A G$ totaux (AGT) - $A G$ des $M G$ solubles dans l'éther diéthylique.

La dissociation des savons a été presque complète avant l'arrivée dans le duodénum. Vu l'importance du $\mathrm{pH}$ sur la dissociation des savons (Sukhija et Palmquist, 1990, J Dairy Sci, 73, 1784-1787), on peut penser que cette dissociation a eu lieu dans la caillette. Au niveau de l'intestin grêle le taux d'association des $A G$ au calcium a été multiplié par 8 . Chez les ruminants, le $\mathrm{pH}$ ne remonte que très progressivement dans l'intestin grêle, la réassociation s'est donc probablement produite dans l'iléon. Le taux d'association n'a pas varié dans le gros intestin, malgré une diminution du $\mathrm{pH}$, compris entre 5,6 et 6,8 (Croom et al, 1985, Can J Anim Sci, 65, 673-681).

En conclusion, le degré d'association des AG de la ration au calcium, sous forme de savons, suit pour l'essentiel l'évolution du $\mathrm{pH}$ dans le tractus digestif. La dissociation est très forte au début de l'intestin grêle, autorisant l'absorption $\operatorname{des} A G$.

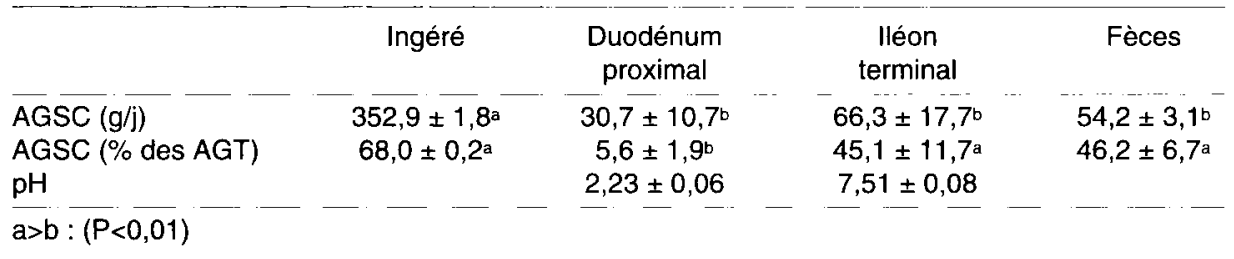

